\title{
The Effect of Dopants on Sintering and Microstructure of Lead-free KNN Ceramics
}

\author{
Ilze SMELTERE ${ }^{1,2}{ }^{*}$, Maija ANTONOVA ${ }^{1}$, Anna KALVANE ${ }^{1}$, \\ Oskars GRIGS ${ }^{2}$, Maris LIVINSH ${ }^{1}$
}

${ }^{1}$ Institute of Solid Sate Physics University of Latvia. 8 Kengaraga Str., Riga, LV-1063, Latvia
2 Biomaterials Innovation and Development Center, Riga Technical University, Pulka 3/3, Riga, LV-1007, Latvia

Received 01 September 2010; accepted 27 February 2011

\begin{abstract}
Lead-free potassium sodium niobate $\left(\mathrm{K}_{0.5} \mathrm{Na}_{0.5}\right) \mathrm{NbO}_{3}(\mathrm{KNN})$ has been prepared via conventional ceramic processing method. The influence of $0.5 \mathrm{wt} \%-1.5 \mathrm{wt} \% \mathrm{MnO}_{2}$ and $\mathrm{WO}_{3}$ addition on the sintering, crystallographic structure, microstructure and dielectric properties of $\mathrm{KNN}$ has been investigated. Optimal sintering temperatures of $\mathrm{KNN}$ ceramics were observed to be in the narrow interval: $1090^{\circ} \mathrm{C}-1110^{\circ} \mathrm{C}$ for $\mathrm{MnO}_{2}$ doped $\mathrm{KNN} ; 1150^{\circ} \mathrm{C}-1170^{\circ} \mathrm{C}$ for pure $\mathrm{KNN}$ and doped with $\mathrm{WO}_{3}$. XRD patterns showed that all the samples have single perovskite structure with monoclinic structure. Microstructure of ceramics was changed greatly by using dopants.

Keywords: potassium sodium niobate, lead-free, oxide additives, piezoelectric ceramics, sintering.
\end{abstract}

\section{INTRODUCTION}

Piezoelectric ceramics are widely used for producing transducers, actuators, sensors etc. Most of these materials such as PZT, PMN-PT have high lead content [1]. Hence lead is toxic there are many restrictions on using certain lead-containing materials in order to protect environment and human health [2].

The latest study shows that ultrasonic wirebonding transducer has been successfully prepared using KNN based lead-free piezoelectric ceramics [3]. It is an evidence that potassium sodium niobate (KNN) with perovskite structure and high Curie temperature $T_{C}\left(\sim 410^{\circ} \mathrm{C}\right)$ could be the candidate for substituting the lead-based materials. This kind of ceramics has been intensively studied in the latest decade especially since the discovery of modified KNN ceramics with properties comparable to those of commercial PZT [4]. However the high volatility of alkali components during the sintering hinders the formation of dense ceramics which leads to poorer dielectric, ferroelectric and piezoelectric properties. Other problem of $\mathrm{KNN}$ based ceramics sintered in air atmosphere is insufficient control of microstructure [5]. Ceramics with uneven grain size distribution are difficult to cut to small dimensions and also polishing of thin samples may be a problem. It is also known that the control over ceramics sintering regime is of remarkable importance for the quality of final product [6]. Various strategies have been used to overcome these problems. A number of studies have been carried out to improve the sinterability by using different sintering aids, for example, a little amount of oxides [7-9]. Substitutions of A- or B-site cations in order to obtain more stable solid solutions [10-12].

In this study KNN ceramics were prepared by conventional ceramic processing method.

Based on our previous research [13] the influence of $0.5 \mathrm{wt} \%-1.5 \mathrm{wt} \% \quad \mathrm{MnO}_{2}$ and $\mathrm{WO}_{3}$ addition on the

\footnotetext{
${ }^{*}$ Corresponding author. Tel.: +371-671-87874; fax.: +371-671-32778.

E-mail address: ilze.smeltere@cfi.lu.lv (I. Smeltere)
}

sintering, crystallographic structure and microstructure of $\left(\mathrm{K}_{0.5} \mathrm{Na}_{0.5}\right) \mathrm{NbO}_{3}$ has been investigated.

\section{EXPERIMENTAL}

KNN ceramics were made by conventional solid-state sintering method. $\mathrm{Na}_{2} \mathrm{CO}_{3} \quad(99.0 \%$, Penta, Czech Republic), $\mathrm{K}_{2} \mathrm{CO}_{3}$ (99.9\%, Penta), $\mathrm{Nb}_{2} \mathrm{O}_{5}$ (99.5\%, Acros, Belgium) were used as starting materials. Powders before weighing were dried at $200{ }^{\circ} \mathrm{C}$ for 4 hours to remove any moisture and further stored in desiccators. Alkali components especially $\mathrm{KNbO}_{3}$ with melting temperature $1039^{\circ} \mathrm{C}$ can evaporate during sintering and it is strongly deliquescent during the period of weighing and ball milling. Homogenization and grinding of raw materials were performed in agate balls mill in anhydrous ethanol for 24 hours. Slurry was dried and calcined in an alumina crucible at $850{ }^{\circ} \mathrm{C}$ for 5 hours. Sintering aids of $0.5 \mathrm{wt} \%-1.5 \mathrm{wt} \% \mathrm{MnO}_{2}$, and $\mathrm{WO}_{3}$ were added to the synthesized KNN powder. The resulting mixtures were ball milled again for 24 hours and dried. The dried powders were mixed with polyvinylalcohol (PVA) binder solution and then uniaxially pressed into disk-shape samples which were sintered in air atmosphere at optimized temperatures for 2 hours, depending on the dopping oxide in the range between $1080^{\circ} \mathrm{C}$ and $1180^{\circ} \mathrm{C}$. The pellets were placed on the platinum foil, and the sintering was performed in a closed alumina crucible to avoid the evaporation of alkali components.

The phase structure was investigated with an X-ray diffraction (XRD) analysis (X'Pert Pro MPD, $\mathrm{CuK}_{\alpha}$ radiation, $2 \theta: 20^{\circ}-80^{\circ}$, step: $0.02^{\circ}$ ). The microstructures of ceramics were studied with a scanning electron microscope (Mira/Tescan). Densities of the samples were measured by Archimedes' method.

For the dielectrical measurements silver paste electrodes were carried up and burned at $600{ }^{\circ} \mathrm{C}$. Temperature dependence of dielectric constant $\varepsilon$ and losses $\tan \delta$ at various frequencies from $130 \mathrm{~Hz}$ to $1 \mathrm{MHz}$ was measured on an impedance analyzer (Hewlett-Packard 
4194A precision LRC meter). Heating and cooling rate was maintained to be $3{ }^{\circ} \mathrm{C} / \mathrm{min}$ in the temperature range from room temperature to $500^{\circ} \mathrm{C}$.

\section{RESULTS AND DISCUSSION}

Fig. 1 shows XRD pattern of pure and doped KNN ceramics sintered via conventional ceramic route. The addition of sintering aids did not affect the crystallographic structure of the ceramics significantly. In all the samples perovskite structure is confirmed, no secondary phase is observed. Cells possess monoclinic symmetry which is in good agreement with the latest studies [14].

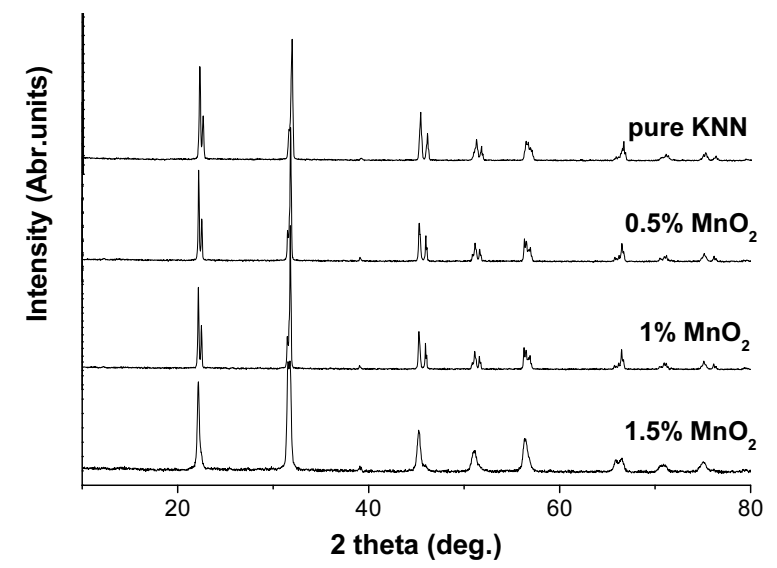

$\mathrm{a}$

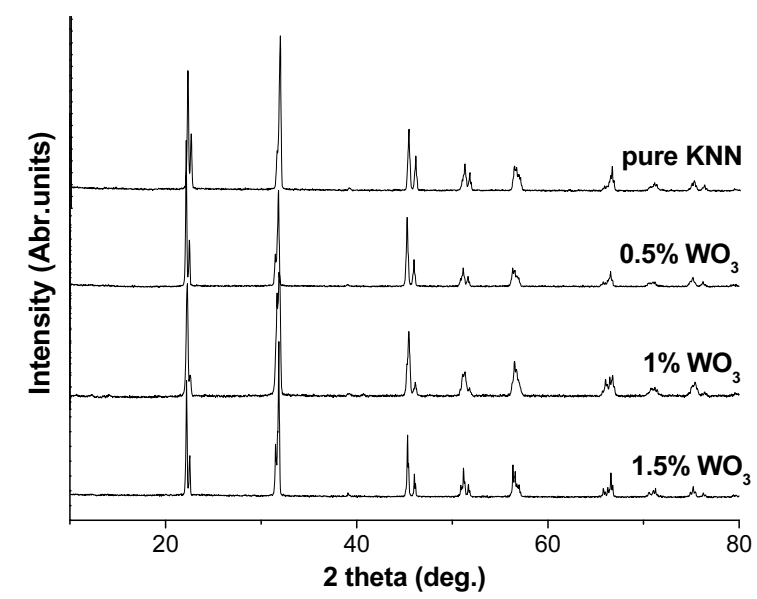

b

Fig. 1. X-ray diffraction patterns for KNN ceramics dopped with $\mathrm{MnO}_{2}$ (a) and $\mathrm{WO}_{3}$ (b)

SEM microstructure analysis (Fig. 2, a-c) showed the influence of the additives on the grain sizes and homogeneity of the sample structure. Characteristic quasi-cubic grains were observed for pure KNN and KNN doped with manganese. Pure KNN has inhomogeneous microstructure with bimodal grain size distribution. The sintering of alkaline niobate based piezoelectric ceramics is usually performed at temperatures near the melting points. As a result, abnormal grain growth tends to occur [15]. On the other hand, adding some oxides with low melting points effectively can lower the sintering temperature and control their grain size which is the case with the addition of $\mathrm{MnO}_{2}$. It suppresses the grain growth and gives rather homogenous microstructure with grain sizes of $1 \mu \mathrm{m}-4 \mu \mathrm{m}$.
The addition of $\mathrm{WO}_{3}$ causes the growth of grains with lamellar structure.

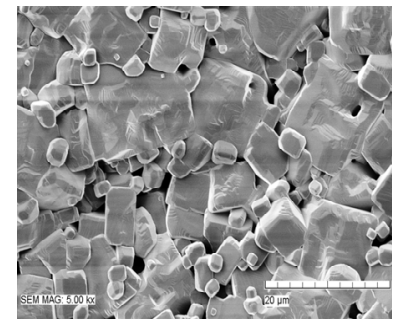

a

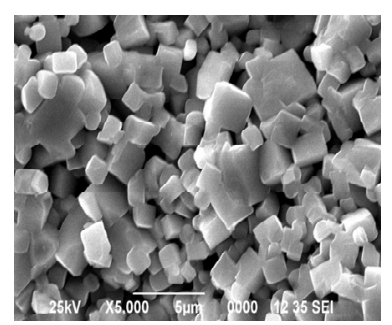

b

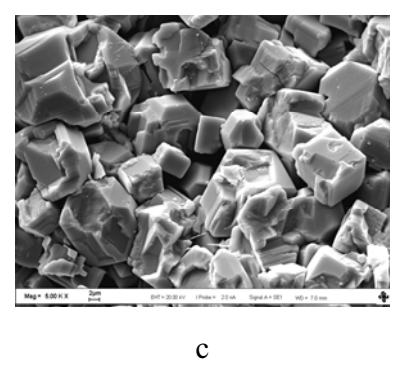

Fig. 2. SEM micrographs: a - pure KNN; b - KNN + 1 wt. \% $\mathrm{MnO}_{2}, \mathrm{c}-\mathrm{KNN}+1$ wt. $\% \mathrm{WO}_{3}$

The dielectric measurements of pure and doped KNN ceramics were made in the frequency range $130 \mathrm{~Hz}-1 \mathrm{MHz}$. The temperature dependence of dielectric permittivity $\varepsilon^{\prime}$ at $1 \mathrm{kHz}$ frequency is showed in Fig. 3. Pure $\mathrm{KNN}$ have two dielectric peaks at around $200^{\circ} \mathrm{C}$ and $400^{\circ} \mathrm{C}$ which correspond to phase transition from orthorhombic to tetragonal and from tetragonal to cubic symmetry, accordingly. The $T_{C}$ as well as values of dielectric permittivity is influenced by the used additive oxides. The peaks are shifted to lower temperatures a little when $\mathrm{MnO}_{2}$ is added.

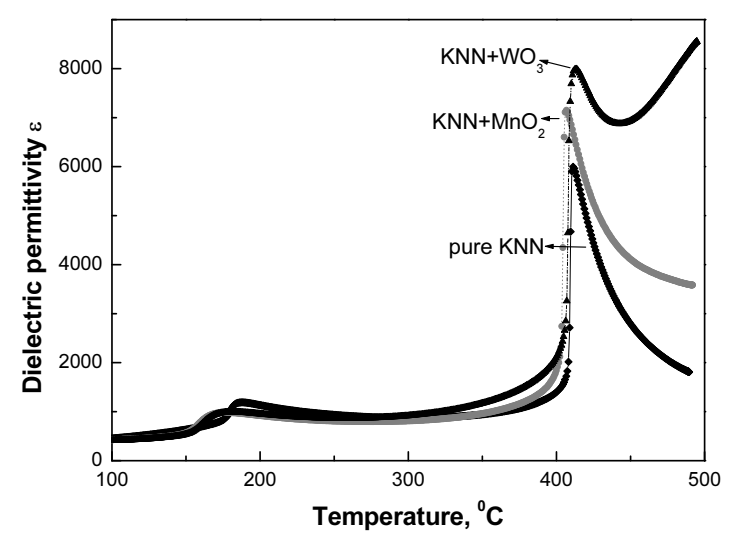

Fig. 3. Temperature dependence of dielectric permittivity $\varepsilon$ ' for samples with 1 wt. \% of dopant

The change in the Curie temperature can be the evidence of doping elements entering the lattice of KNN ceramics. According to the XRD data however the pure perovskite phase was obtained for all the samples. Also the diffraction angles had not changed pointing that the lattice parameters are changed very little. It is probably due to the low level of added doping oxides. When $\mathrm{WO}_{3}$ is used the displacement is negligible. The dielectric constant is 6000 for pure $\mathrm{KNN}$ obtained at $1170^{\circ} \mathrm{C}$ for 2 hours. Doped 
KNN ceramic samples have higher dielectric constant. It is about 7500 and similar for ceramic samples doped with $1 \mathrm{wt} . \% \mathrm{MnO}_{2}$ (sintered at $1100^{\circ} \mathrm{C}$ for 2 hours) and 8000 doped with $1 \mathrm{wt} . \% \mathrm{WO}_{3}\left(1170^{\circ} \mathrm{C}\right.$ for 2 hours).

The increase in dielectric permittivity values by doping can be explained with higher density of the samples and more homogeneous microstructure.

Table 1. Dielectric permittivity $\varepsilon^{\prime}$ and $T_{c}$ dependence on sintering temperature

\begin{tabular}{|c|c|c|c|}
\hline & Sintering $T,{ }^{\circ} \mathrm{C}$ & $\varepsilon_{\max }$ & $T_{c}$ \\
\hline \multirow{3}{*}{$\mathrm{KNN}+\mathrm{MnO}_{2}$} & 1100 & 7150 & 407 \\
\cline { 2 - 4 } & 1110 & 7460 & 402 \\
\cline { 2 - 4 } & 1120 & 7000 & 407 \\
\hline \multirow{3}{*}{$\mathrm{KNN}+\mathrm{WO}_{3}$} & 1160 & 6350 & 413 \\
\cline { 2 - 4 } & 1170 & 8000 & 414 \\
\cline { 2 - 4 } & 1180 & 6470 & 414 \\
\hline
\end{tabular}

Table 1 shows the maximum dielectric permittivity $\varepsilon$ ' value dependence on sintering temperature of the ceramic samples. It shows the importance of choice the optimal sintering regimens for ceramics based on KNN.

\section{CONCLUSIONS}

The solid solution based on $\left(\mathrm{K}_{0.5} \mathrm{Na}_{0.5}\right) \mathrm{NbO}_{3}$ ceramics were prepared by conventional ceramic processing technology. Optimal sintering regime for $\mathrm{KNN}$ ceramics with single-phase perovskite structure and the monoclinic symmetry at room temperature were established. KNN solid solution samples with the aid of $0.5 \mathrm{wt} \%-1.5 \mathrm{wt} \%$ of $\mathrm{MnO}_{2}$ and $\mathrm{WO}_{3}$ were obtained. $\mathrm{MnO}_{2}$ reduced sintering temperature for about $40^{\circ} \mathrm{C}-50^{\circ} \mathrm{C}$. The optimal sintering temperature regime for these samples is in the range $1100^{\circ} \mathrm{C}-1130^{\circ} \mathrm{C}$. The microstructure of the samples was remarkably changed by addition of sintering aids. The grain size was reduced and more homogeneous distribution of grain sizes was achieved by addition of $\mathrm{MnO}_{2}$. Oxide additive increased dielectric permittivity $\varepsilon$ ' from 6000 for pure $\mathrm{KNN}$ up to 8000 for doped with $\mathrm{WO}_{3}$.

\section{Acknowledgements}

This work has been partly supported by the European Social Fund within the project "Multidisciplinary Research in Biomaterials Technology of New Scientist Group", No.2009/0199/1DP/1.1.1.2.0/09/APIA/VIAA/090 (PVS ID 1380).

\section{REFERENCES}

1. Takenaka, T., Nagata, H. Current Status and Prospects of Lead-free Piezoelectric Ceramics Journal of European Ceramic Society 25 2005: pp. 2693-2700.
2. Directive 2002/96/EC of the European Parliament and of the Council on Waste Electrical and Electronic Equipment (WEEE).

3. Lee, T., Kwok, K. W., Li, H. L., Chan, H. L.W. Lead-free Alkaline Niobate-based Transducer for Ultrasonic Wirebonding Applications Sensors and Actuators A 150 2009: pp. 267-271.

4. Saito, Y., Takao, H., Tani, T., Nonoyama, T., Takatori, K., Homma, T., Nagaya, T., Nakamura, M. Lead-free Piezoelectric Ceramics Nature 432 2004: pp. 84-87.

5. Malic, B., Bernard, J., Bencan, A., Kosec, M. Influence of Zirconia Addition on the Microstructure of $\mathrm{K}_{0.5} \mathrm{Na}_{0.5} \mathrm{NbO}_{3}$ Ceramics Journal of European Ceramics Society 28 (6) 2008: pp. $1191-1196$.

6. Du, H., Li, Z., Tang, F., Qu, S., Pei, Z., Zhou, W. Preparation and Piezoelectric Properties of $\left(\mathrm{K}_{0.5} \mathrm{Na}_{0.5}\right) \mathrm{NbO}_{3}$ Lead-free Piezoelectric Ceramics with Pressure-less Sintering Materals Science and Engineering B 131 2006: pp. $83-87$.

7. Li, E., Kakemoto, H., Wada, S., Tsurumi, T. Influence of $\mathrm{CuO}$ on the Structure and Piezoelectric Properties of Alkaline Niobate-Based Lead-Free Ceramics Journal of American Ceramic Society 90 (6) 2007: pp. 1787-1791.

8. Malic, B., Bernard, J., Holc, J., Jenko, D., Kosec, M. Alkaline-Earth Doping in (K,Na) $\mathrm{NbO}_{3}$ Based Piezoceramics Journal of European Ceramic Society 252005 : pp. 2707-2711.

9. Park, S. H., $\quad$ Ahn, C. W., Nahm, S., Song, J. S. Microstructure and Pyroelectric Properties of ZnO-Added $\left(\mathrm{Na}_{0.5} \mathrm{~K}_{0.5}\right) \mathrm{NbO}_{3}$ Ceramics Japanese Journal of Applied Physics 43 (8B) 2004: pp. 1072-1074.

10. Dambekalne, M, Antonova, M, Livinsh, M, Kalvane, A, Mishnov, A, Smeltere, I, Krutohvostov, R, Bormanis, K, Sternberg, A. Synthesis and Characterization of Sbsubstituted $\left(\mathrm{K}_{0.5} \mathrm{Na}_{0.5}\right) \mathrm{NbO}_{3} \quad$ Piezoelectric Ceramics Integrated Ferroelectrics 102 2008: pp. 52-61.

11. Zhang, S., Xia, R., Shrout, T. R., Zang, G., Wanag, J. Characterization of Lead-free $\left(\mathrm{K}_{0.5} \mathrm{Na}_{0.5}\right) \mathrm{NbO}_{3}-\mathrm{LiSbO}_{3}$ Piezoceramic Solid State Communications 141 2007: pp. $675-679$.

12. Rubio-Marcos, F., Ochoa, P., Fernandez, J. F. Sintering and Properties of Lead-free $(\mathrm{K}, \mathrm{Na}, \mathrm{Li})(\mathrm{Nb}, \mathrm{Ta}, \mathrm{Sb}) \mathrm{O}_{3}$ Journal of European Ceramic Society 27 2007: pp. 4125-4129.

13. Smeltere, I., Dambekalne, M., Livinsh, M., Dunce, M., Mishnov, A., Zauls, V. Sintering of Lead-free $\left(\mathrm{K}_{0.5} \mathrm{Na}_{0.5}\right) \mathrm{NbO}_{3}$ Based Solid Solution Integrated Ferroelectrics 108 2009: pp. 46-56.

14. Tellier, J., Malic, B., Dkhil, B., Jenko, D., Cilensek, J., Kosec, M. Crystal Structure and Phase Transitions of Sodium Potassium Niobate Perovskites Solid State Sciences 11 2009: pp. 320-324.

15. Kakimoto, K., Ando, K., Ohsato, H. Grain Size Control of Lead-free $\mathrm{Li}_{0.06}\left(\mathrm{Na}_{0.5} \mathrm{~K}_{0.5}\right)_{0.94} \mathrm{NbO}_{3}$ Piezoelectric Ceramics by $\mathrm{Ba}$ and $\mathrm{Ti}$ Doping Journal of European Ceramics Society 30 2010: pp. 295-299. 